\title{
Feeding Response to Tea Saponin in Chicks Given Diet Selection
}

\author{
Hiroshi Ueda and Gen Shigemizu
}

Faculty of Agriculture, Ehime University, Matsuyama-shi 790-8566, Japan

\begin{abstract}
In order to evaluate the involvement of taste in the decreased feed intake due to tea saponin, the preference for a diet containing saponin or cholesterol was studied in chicks given diet selection. When chicks were fed the basal diet added with $1 \%$ saponin ad libitum for 4-6h, feed intake decreased within $2 \mathrm{~h}$ and the decrease in feed intake was became severer with time. Chicks given the choice between the basal and saponin-added diets for $12 \mathrm{~h}$ selected the basal diet exclusively during 4-12 h, but there were no significant differences in feed intake between the two diets during the first $4 \mathrm{~h}$. Chicks preferred the basal diet to the saponin-added diet when the two-choice preference test was prolonged to $8 \mathrm{~d}$. However, there were large individual differences in the feeding response among chicks ; some chicks selected the basal diet from the start of the test, but others needed more time to select the basal diet. These individual differences were disappeared with fixing the feeder positions rather than changing the feeder positions every day. The deleterious effect due to tea saponin did not occur when equal amounts of cholesterol were supplemented to the saponin-added diet. However, chicks did not show the special preference for cholesterol, when they were given the choice between the basal diet and a diet containing $1 \%$ cholesterol for $12 \mathrm{~h}$ or between the basal diet and a diet containing saponin plus cholesterol at $1 \%$ levels for $8 \mathrm{~d}$. These results suggest that chicks can recognize the presence of saponin, but taste is not a major determinant responsible for the depression in feed intake due to saponin.
\end{abstract}

Key words : saponin, cholesterol, diet selection, feeder position, taste

\section{Introduction}

High levels of alfalfa meal or protein concentrate prepared from alfalfa leaf in a diet depress the growth rate of chicks and egg production of layers (Anderson, 1957 ; Heywang and Thompson, 1959 ; Ohshima and Ueda, 1984). Peterson (1950) suggested that a toxic fraction of alfalfa meal was saponin because the toxic fraction had the hemolytic and foaming properties. Furthermore, the concurrent feeding of cholesterol reverses growth depression due to alfalfa meal or leaf protein concentrate (Anderson, 1957 ; Peterson, 1950 ; Ueda et al., 1986). These results have led to the conclusion that alfalfa saponin is major factor causing growth depression (Heywang and Bird, 1954 ; Ueda et al., 1996).

Saponins are glycosides widely distributed in the plant kingdom, and some saponins are known to adversely affect chick growth performance (Fenwick and Oakenfull, 1983 ; Oakenfull, 1981 ; Price et al., 1987). Growth-depressing effect of Gypsophila, Quillaja or tea saponin as well as alfalfa saponin has been demonstrated in chicks 
(Ueda, 1992 ; Ueda et al., 1996 ; Ueda and Shigemizu, 1998 ; Ueda and Tanoue, 2000). Results obtained from these experiments indicate that the growth depression due to saponins is attributed to the decreased feed intake, but it is unknown how saponins depress feed intake. Since these saponins have bitter taste, palatability was suggested to be a primary factor affecting feed intake (Cheek et al., 1978, 1983 ; Leamaster and Cheek, 1979). However, chickens given diet selection were less sensitive to the presence of alfalfa saponin or quinine sulfate than rats (Cheeke et al., 1978 ; Leamaster and Cheek, 1979). Nevertheless, depression in feed intake of chicks given alfalfa leaf protein concentrate prepared from high-saponin variety was extremely severer than that in rats (Ohshima and Ueda, 1984). Recent studies have shown that the deleterious effect of dietary alfalfa or tea saponin and the alleviative effect of cholesterol are observed even when each supplement is introduced into the proventriculus to avoid the effect of taste (Ueda et al., 1996 ; Ueda and Shigemizu, 1998). Besides, there has been no evidence that cholesterol alters palatability or taste. These results suggest that palatability or taste is not a primary determinant responsible for the decreased feed intake due to saponins. The present experiment was conducted with chicks to evaluate the involvement of taste in the adverse effect of tea saponin on feed intake using a two-choice preference test.

\section{Materials and Methods}

\section{Animals and Diets}

Single Comb White Leghorn male chicks were maintained in a room with constant temperature $\left(30^{\circ} \mathrm{C}\right)$ and continuous lighting. They were raised on a commercial chick starter ration in wire-mesh cages until the experiment. Prior to the experiment, chicks were fed the basal diet for about $2 \mathrm{~h}$ in order to accustom the semi-purified diet. At the beginning of the experiment, chicks were deprived of feed overnight (for $15 \mathrm{~h}$ ) and weighed individually. The necessary number of chicks was selected from the stock and distributed to experimental groups with similar body weights. During the experimental period, chicks were housed individually in metabolism cages. In two-choice preference tests, each cage was equipped with two identical feeders, and drinker was located between feeders. Feed intake was measured at appropriate intervals and then diets were added to make up for those consumed by chicks so that two feeders distributed almost equal amounts of diets.

The composition of basal diet containing $20 \%$ crude protein was as follows ( $\mathrm{g} /$ $\mathrm{kg}$ ) ; casein 209.1, L-arginine hydrochloride 12.4, L-methionine 3.9, glycine 4.6, choline chloride 2.0, vitamin mixture 1.0 (Ueda, 1997), mineral mixture 65.2 (Ueda, 1997), corn oil 30.0, cellulose 30.0, cornstarch 200.0 and glucose 441.8. Tea saponin (Wako Pure Chemical Ind., Osaka, Japan) and cholesterol were added to the basal diet at the expense of equal amounts of glucose.

Experiment 1

Chicks weighing about $95 \mathrm{~g}$ were divided into three experimental groups of six chicks each. One group had free access to the basal diet for $10 \mathrm{~h}$. Another two groups were given two diets sequentially; a diet containing $1 \%$ tea saponin with or 
without $1 \%$ cholesterol. The first and second diets were fed for 4 and $6 \mathrm{~h}$, respectively. Feed intake was recorded at 2 -h intervals.

Experiments 2 and 3

In experiment 2, 12 chicks weighing about $90 \mathrm{~g}$ were given a choice between the basal diet and a diet containing $1 \%$ saponin (trial 1 ) or between the basal diet and a diet containing $1 \%$ cholesterol (trial 2) for $12 \mathrm{~h}$. In experiment 3, 14 chicks weighing about $83 \mathrm{~g}$ were subjected to the same preference test, but the two feeders distributed only the basal diet in order to investigate the effect of the feeder positions. Feed intake was recorded at 4-h intervals and the feeder positions were fixed throughout the experiment.

Experiments 4 and 5

In experiment 4, 24 chicks weighing about $59 \mathrm{~g}$ were used. Twelve chicks were given a choice between the basal diet and the $1 \%$ saponin-added diet for $8 \mathrm{~d}$. Another 12 chicks were given the basal diet and a diet supplemented with $1 \%$ tea saponin plus $1 \%$ cholesterol. Feed intake and body weight were recorded every day, after which feeder positions were switched. In experiment 5, 32 chicks weighing about $55 \mathrm{~g}$ were offered a choice between the basal diet and a diet containing $0.5 \%$ saponin for $8 \mathrm{~d}$. Feeders of 16 chicks were fixed, and those of the other 16 chicks were changed every day. Feed intake and body weight were recorded every day.

Statistical analysis

Data were analyzed statistically by analysis of variance, followed by Tukey's multiple range test or Student' $t$ test (Yoshida, 1975). The latter was used when the number of replications in the treatment was different (Experiment 4).

\section{Results and Discussion}

Results of experiment 1 are given in Table 1. Feed intake in chicks given the basal diet and the diet containing saponin plus cholesterol for $4 \mathrm{~h}$ were compatible. The removal of cholesterol from the latter diet decreased feed intake within $2 \mathrm{~h}$, and supplementing cholesterol to the saponin-added diet alleviated the depressed feed intake within $2 \mathrm{~h}$. The adverse effect of saponin and the alleviative effect of cholesterol on

Table 1. Feed intake in chicks fed a diet containing $1 \%$ tea saponin (TS) with or without $1 \%$ cholesterol (CHOL) sequentially in Experiment $1^{1)}$

\begin{tabular}{|c|c|c|c|c|c|c|}
\hline \multicolumn{2}{|c|}{ Diet } & \multicolumn{5}{|c|}{ Feed intake } \\
\hline First & Second & \multicolumn{2}{|c|}{ First period } & \multicolumn{3}{|c|}{ Second period } \\
\hline (4 h) & $(6 \mathrm{~h})$ & $0-2 \mathrm{~h}$ & $2-4 \mathrm{~h}$ & $0-2 \mathrm{~h}$ & $2-4 \mathrm{~h}$ & $4-6 \mathrm{~h}$ \\
\hline & & & & (g/chick) & & \\
\hline Basal & Basal & $4.2 \pm 0.2^{\mathrm{b}}$ & $2.2 \pm 0.1^{\mathrm{b}}$ & $3.5 \pm 0.1^{\mathrm{b}}$ & $3.6 \pm 0.2^{\mathrm{b}}$ & $3.7 \pm 0.1^{\mathrm{b}}$ \\
\hline $\mathrm{TS}+\mathrm{CHOL}$ & TS & $4.0 \pm 0.2^{\mathrm{b}}$ & $2.3 \pm 0.2^{\mathrm{b}}$ & $1.8 \pm 0.2^{\mathrm{a}}$ & $1.3 \pm 0.1^{\mathrm{a}}$ & $1.0 \pm 0.1^{\mathrm{a}}$ \\
\hline TS & $\mathrm{TS}+\mathrm{CHOL}$ & $1.7 \pm 0.1^{\mathrm{a}}$ & $1.2 \pm 0.2^{\mathrm{a}}$ & $3.6 \pm 0.6^{\mathrm{b}}$ & $4.1 \pm 0.7^{\mathrm{b}}$ & $3.7 \pm 0.4^{\mathrm{b}}$ \\
\hline
\end{tabular}


feed intake were observed in 10-d feeding experiment (Ueda and Shigemizu, 1998 ; Ueda and Tanoue, 2000). The present result showed that chicks could rapidly respond to tea saponin by decreasing feed intake, and this response readily disappeared with cholesterol. The decrease in feed intake due to saponin was rather mild during the first $2 \mathrm{~h}$ as compared with the following period $(2-4$ or $4-6 \mathrm{~h})$, irrespective of whether the saponin-added diet was given from the start of the experiment ( $1.7 \mathrm{vs} .1 .2 \mathrm{~g})$ or after the consumption of the other diet ( 1.8 vs. 1.3 or $1.0 \mathrm{~g}$ ). A similar and clear-cut result was observed in chicks with heavier body weights (Ueda, 2001).

In experiment 2, chicks were given two-choice preference tests. As shown in Table 2, chicks given the basal and saponin-added diets during 12-h preferred the former in trial 1. However, there were no statistical differences in feed intake between both diets during the first $4 \mathrm{~h}$, although feed intake of the saponin-added diet was $56 \%$ of the basal. After that, chicks avoided the saponin-added diet and consequently feed intake of the saponin-added diet during 4-12h was $26 \%$ of the basal. This result accorded with the results obtained in experiment 1 and others (Ueda, 2001) that the decrease in feed intake due to saponin became severer with time. We already reported that $0.1 \mathrm{~g}$ of tea saponin introduced to the proventriculus by capsules to avoid the effect of taste suppressed feed intake over $24 \mathrm{~h}$ after the administration, despite the fact that chicks were given free access to the basal diet (Ueda and Shigemizu, 1998). These results indicate that taste is not a primary factor decreasing feed intake in chicks given tea saponin.

When chicks were given the choice between the basal diet and the diet containing $1 \%$ cholesterol in trial 2 (Table 2), they consumed the basal diet exclusively during the first $4 \mathrm{~h}$, after which there were no differences in feed intake between both diets. Since feed intake during the first $4 \mathrm{~h}(9.9 \mathrm{~g} / \mathrm{chick})$ and $4-12 \mathrm{~h}(9.6 \mathrm{~g} / \mathrm{chick})$ was comparable, owing to the overnight fasting, feed intake of the basal diet during $12 \mathrm{~h}$ was significantly higher than that of the cholesterol-added diet. However, there is some doubt to

Table 2. Feed intake in chicks given the choice between the basal diet and a diet containing $1 \%$ tea saponin or between the basal diet and a diet containing $1 \%$ cholesterol in Experiment $2^{1}$

\begin{tabular}{|c|c|c|c|c|}
\hline \multirow[t]{2}{*}{ Diet } & \multicolumn{4}{|c|}{$\begin{array}{c}\text { Feed intake } \\
\text { Hours after feeding }\end{array}$} \\
\hline & $0-4$ & $4-8$ & $8-12$ & $0-12$ \\
\hline Trial 1 & \multicolumn{4}{|c|}{ (g/chick) } \\
\hline Basal & $5.5 \pm 1.0$ & $3.0 \pm 0.7$ & $3.2 \pm 0.5$ & $11.6 \pm 1.7$ \\
\hline Saponin & $3.1 \pm 0.7$ & $0.8 \pm 0.2^{* *}$ & $0.8 \pm 0.2^{* *}$ & $4.6 \pm 0.8^{* *}$ \\
\hline Trial 2 & & & & \\
\hline Basal & $7.4 \pm 0.6$ & $2.2 \pm 0.6$ & $1.8 \pm 0.4$ & $11.4 \pm 1.0$ \\
\hline Cholesterol & $2.5 \pm 0.5^{* *}$ & $2.9 \pm 0.7$ & $2.7 \pm 0.3$ & $8.1 \pm 1.0^{*}$ \\
\hline
\end{tabular}

1) Values are mean $\pm \mathrm{SE}$ for 12 chicks. ${ }^{*}$ and ${ }^{* *}$; Significantly different from the basal at $\mathrm{P}<0.05$ and 0.01 , respectively. 
conclude that chicks avoid the cholesterol-added diet, because nutritive value and feed intake of the cholesterol-added diet are identical to those of the basal diet in the $a d$ libitum feeding (Ueda and Shigemizu, 1998 ; Ueda and Tanoue, 2000). This result may indicate that the short-term preference test used in experiment 2 is not the appropriate approach to compare the preference for diets with adequate nutritive values.

In order to examine this possibility, chicks were subjected to a similar two-choice preference test in experiment 3 , but two feeders distributed only the basal diet. The feeder positions were fixed during the test period. Feeders from which chicks ate their diet exclusively during the first $4 \mathrm{~h}$ were referred to as Feeder A, and the other Feeder B (Table 3). We expected that feed intake from each feeder was equal when chicks were given the same diet. However, there were statistical differences in feed intake from two feeders during the $0-4$ and $0-12 \mathrm{~h}$ periods. Detailed analysis of data showed that there were two types of feeding pattern among chicks. Seven out of 14 chicks ate their diet entirely from particular feeders (Feeder A) throughout the experiment (Persistent type in Table 3). On the other hand, the remaining 7 chicks ate the diet from Feeder A during the first $4 \mathrm{~h}$, after which they selected the diet from Feeder B. Consequently, feed intake from Feeders A and B during $12 \mathrm{~h}$ was equal (Non-persistent type). This result implied that the feeding response of some chicks was susceptible to the feeder positions, which affected the results of the preference test, especially when

Table 3. Feed intake in chicks given the basal diet from two feeders in Experiment $3^{1)}$

\begin{tabular}{|c|c|c|c|c|}
\hline \multirow[t]{2}{*}{ Feeding type $\mathrm{p}^{2)}$} & \multicolumn{4}{|c|}{$\begin{array}{c}\text { Feed intake } \\
\text { Hours after feeding }\end{array}$} \\
\hline & $0-4$ & $4-8$ & $8-12$ & $0-12$ \\
\hline & \multicolumn{4}{|c|}{ (g/chick) } \\
\hline \multicolumn{5}{|l|}{ Total $(n=14)$} \\
\hline Feeder A & $7.9 \pm 0.6^{* *}$ & $2.9 \pm 0.6$ & $2.1 \pm 0.4$ & $12.9 \pm 1.0^{* *}$ \\
\hline Feeder B & $2.2 \pm 0.5$ & $2.4 \pm 0.6$ & $2.6 \pm 0.5$ & $6.4 \pm 1.0$ \\
\hline \multicolumn{5}{|l|}{ Persistent $(\mathrm{n}=7)$} \\
\hline Feeder A & $9.0 \pm 0.9^{* *}$ & $4.3 \pm 0.7^{* *}$ & $2.9 \pm 0.5$ & $16.1 \pm 0.8^{* *}$ \\
\hline Feeder B & $1.7 \pm 0.9$ & $0.4 \pm 0.4$ & $1.3 \pm 0.6$ & $3.4 \pm 0.9$ \\
\hline \multicolumn{5}{|c|}{ Non-persistent $(\mathrm{n}=7)$} \\
\hline Feeder A & $6.9 \pm 0.7^{* *}$ & $1.5 \pm 0.7$ & $1.4 \pm 0.4^{* *}$ & $9.7 \pm 0.6$ \\
\hline Feeder B & $2.7 \pm 0.5$ & $3.5 \pm 0.7$ & $3.1 \pm 0.2$ & $9.3 \pm 0.7$ \\
\hline
\end{tabular}

1) Values are mean $\pm \mathrm{SE}$ for 14 or 7 chicks. Feeders from which chicks consumed their diet exclusively during the first $4 \mathrm{~h}$ are referred to as Feeder A. ${ }^{* *}$; Feed intake from Feeder $\mathrm{A}$ is significantly different from Feeder $\mathrm{B}$ at $\mathrm{P}<0.01$.

${ }^{2)}$ Chicks of persistent type stayed with the feeder positions, so that they ate their diet from particular feeders during $12 \mathrm{~h}$. On the other hand, feed intake from Feeders $\mathrm{A}$ and $\mathrm{B}$ during $12 \mathrm{~h}$ was equal in non-persistent type. 
Table 4. Feed intake and body weight gain in chicks given the choice between the basal diet and a diet containing $1 \%$ tea saponin (TS) or between the basal diet and a diet containing $1 \%$ TS plus $1 \%$ cholesterol (CHOL) in Experiment $4^{11}$

\begin{tabular}{|c|c|c|c|c|c|}
\hline \multirow{2}{*}{$\underset{\text { type }^{2)}}{\text { Feeding }}$} & \multirow{2}{*}{ Diet } & \multicolumn{2}{|c|}{ Feed intake ( $\mathrm{g} / \mathrm{chick})$} & \multicolumn{2}{|c|}{ Body weight gain $(\mathrm{g} / \mathrm{chick}$} \\
\hline & & $0-4 \mathrm{~d}$ & $0-8 \mathrm{~d}$ & $0-4 d$ & $0-8 \mathrm{~d}$ \\
\hline & \multicolumn{5}{|c|}{ Trial 1 (Basal diet vs. diet containing TS) ${ }^{3)}$} \\
\hline Total (12) & $\begin{array}{l}\text { Basal } \\
\text { TS }\end{array}$ & $\begin{array}{r}38.9 \pm 4.7 \\
8.1 \pm 1.1\end{array}$ & $\begin{array}{r}105.9 \pm 8.0 \\
10.2 \pm 1.6\end{array}$ & $27.6 \pm 3.5$ & $60.9 \pm 4.8$ \\
\hline Type I (7) & $\begin{array}{l}\text { Basal } \\
\text { TS }\end{array}$ & $\begin{array}{r}50.4 \pm 4.0 \\
5.8 \pm 1.1\end{array}$ & $\begin{array}{r}124.5 \pm 4.8 \\
6.6 \pm 1.2\end{array}$ & $35.8 \pm 3.2$ & $72.5 \pm 3.3$ \\
\hline \multirow[t]{2}{*}{ Туре ПI (5) } & $\begin{array}{l}\text { Basal } \\
\text { TS }\end{array}$ & $\begin{array}{l}22.9 \pm 2.4 \\
11.2 \pm 0.9\end{array}$ & $\begin{array}{l}79.9 \pm 9.1 \\
15.3 \pm 1.3\end{array}$ & $16.1 \pm 2.1$ & $44.7 \pm 3.8$ \\
\hline & \multicolumn{5}{|c|}{ Trial 2 (Basal diet vs. diet containing TS plus CHOL) $)^{4)}$} \\
\hline Total (12) & $\begin{array}{l}\text { Basal } \\
\text { TS + CHOL }\end{array}$ & $\begin{array}{l}32.5 \pm 6.3 \\
18.1 \pm 4.3\end{array}$ & $\begin{array}{l}83.4 \pm 13.0 \\
41.7 \pm 11.0\end{array}$ & $34.6 \pm 1.5$ & $77.2 \pm 1.4$ \\
\hline Type I (6) & $\begin{array}{l}\text { Basal } \\
\text { TS }+ \text { CHOL }\end{array}$ & $\begin{array}{r}52.0 \pm 2.3 \\
5.4 \pm 1.6\end{array}$ & $\begin{array}{r}124.3 \pm 4.0 \\
6.5 \pm 2.2\end{array}$ & $38.0 \pm 1.1$ & $79.3 \pm 1.6$ \\
\hline Type I -SC (3) & $\begin{array}{l}\text { Basal } \\
\text { TS + CHOL }\end{array}$ & $\begin{array}{r}5.0 \pm 2.9 \\
42.9 \pm 1.5\end{array}$ & $\begin{array}{l}27.5 \pm 2.5 \\
92.9 \pm 2.0\end{array}$ & $33.6 \pm 2.6$ & $75.1 \pm 0.5$ \\
\hline Type III (3) & $\begin{array}{l}\text { Basal } \\
\text { TS + CHOL }\end{array}$ & $\begin{array}{l}21.0 \pm 2.2 \\
22.6 \pm 0.3\end{array}$ & $\begin{array}{l}57.4 \pm 3.3 \\
64.8 \pm 4.6\end{array}$ & $34.1 \pm 1.9$ & $77.2 \pm 4.1$ \\
\hline
\end{tabular}

1) Values are mean \pm SE. Figures in parentheses are numbers of chicks to calculate these values.

2) See footnote in Figure 1.

${ }^{3)}$ Feed intake of each test diet and body weight gain are statistically different $(\mathrm{P}<$ 0.01 ) between Types I and II.

4) Feed intake of each test diet is statistically different $(\mathrm{P}<0.01)$ among Types I, I -SC and III.

two diets have the same nutritive values.

In order to obtain the precise information from the two-choice preference test, the experimental period was prolonged to $8 \mathrm{~d}$ and the feeder positions were changed every day in experiment 4 . In trial 1 , chicks were offered the choice between the basal diet and the $1 \%$ saponin-added diet. Results were given in Table 4. Chicks preferred the control diet predominantly to the saponin-added diet during $8 \mathrm{~d}$ (105.9 vs. $10.2 \mathrm{~g}$ ). However, large individual differences in the feeding behavior were observed, particularly during the first $4 \mathrm{~d}$. Such different feeding responses were classified into Types I and II as shown in Table 4, and Figure 1 shows the typical feeding pattern in each type. Seven out of 12 chicks ate the basal diet predominantly, regardless of the changing of the feeder positions every day, and grew linearly throughout the test period (Type I). However, the other 5 chicks more ate the saponin-added diet than Type I during the first $4 \mathrm{~d}$, probably due to the strong preference for the feeder positions, after which they selected the basal diet (Type II). When these chicks selected the saponin-added diet, body weight gain was depressed (Figure 1). Consequently, total feed intake and body 


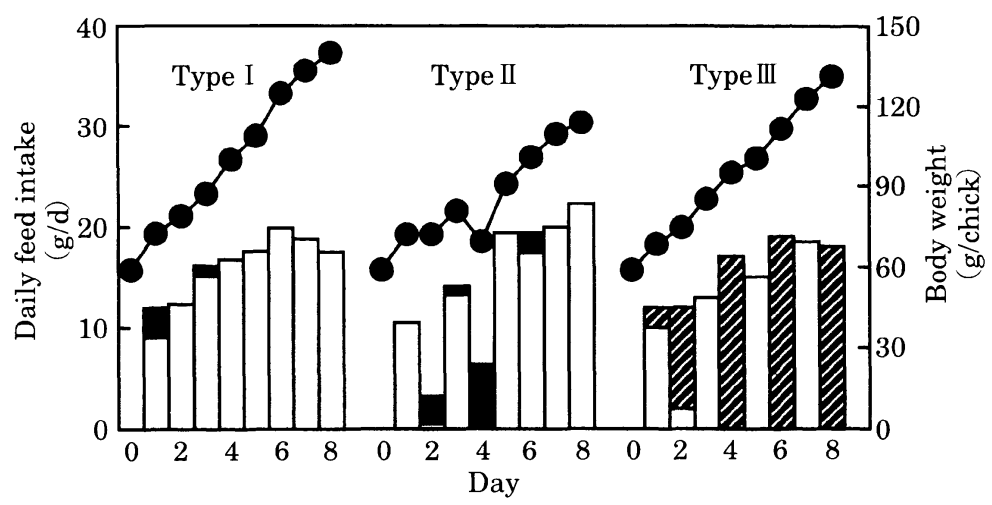

Fig. 1. Different types of daily feed intake and body weight change in chicks given the two-choice preference test in Experiment 4. Chicks were given the choice between the basal diet $(\square)$ and a diet containing $1 \%$ tea saponin $(\boldsymbol{\square})$ or a diet containing $1 \%$ tea saponin plus $1 \%$ cholesterol $(\mathbb{G})$. Type I ate the basal diet predominantly and grew linearly throughout the experiment, regardless of the changing of feeder positions every day. Type II failed to eat the adequate amounts of the basal diet during the first $4 \mathrm{~d}$, and when they selected the saponin-added diet, body weight gain was depressed. Type III stayed with feeder positions, so that they consumed equal amounts of diets from two feeders. Body weight was not affected by the diet they selected, since the nutritive value of two diets was comparable.

weight gain of Type II during 0-4 and 0-8 d were significantly inferior to those of Type I.

In trial 2, chicks were given the choice between the basal diet and the diet supplemented with $1 \%$ saponin plus $1 \%$ cholesterol (Table 4 ). As compared with the result of trial 1, feed intake of the basal diet during $8 \mathrm{~d}$ decreased and in turn that of the diet containing saponin plus cholesterol increased ( 83.4 vs. $41.7 \mathrm{~g}$, respectively). Three feeding patterns were observed. Six chicks selected the basal diet throughout the test period (Type I), whereas three chicks preferred the diet containing saponin plus cholesterol to the basal diet (Type I-SC). The remaining three chicks that were classified into type III in Figure 1 consumed almost equal amounts of diets from two feeders, because feeders were switched every day but these chicks stayed with the feeder positions rather than diet composition. In all cases, the growth rate of chicks was unaffected by the diet they selected, since the nutritive value of two diets was comparable (Ueda and Shigemizu, 1998 ; Ueda and Tanoue, 2000). The result of trial 2, along with the result of the short-term preference test in experiment 2 , indicated that chicks did not have the special preference for cholesterol.

As shown in Table 1, chicks responded rapidly to the saponin-added diet by decreasing feed intake when each diet was given singly. In the two-choice preference test, chicks selected overwhelmingly basal diet. Thus, it seems likely that chicks 


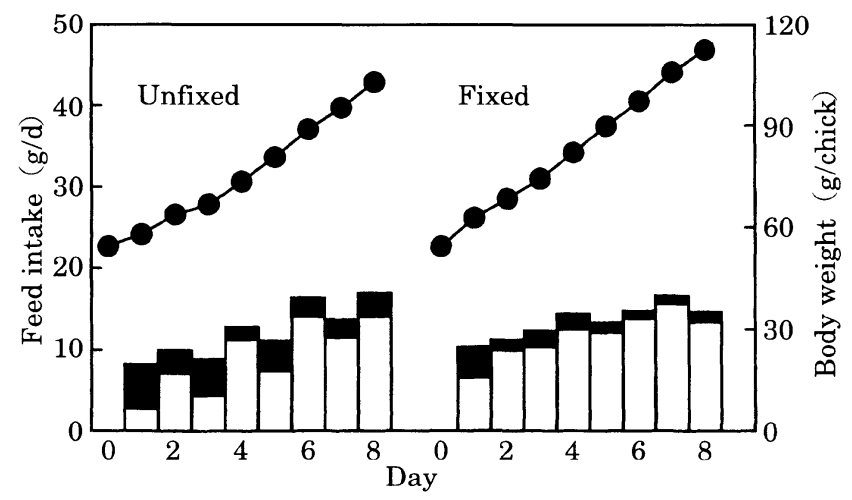

Fig. 2. Daily feed intake and body weight change $(\mathbf{)})$ in chicks given the two-choice preference test in Experiment 5.

Values are mean for 16 chicks. Chicks were given the choice between the basal diet $(\square)$ and a diet containing $0.5 \%$ tea saponin (ם). Feeder positions of one group were changed every day (Unfixed) and those of the other group were fixed (Fixed).

recognize the presence of saponin in the diet. However, some chicks, such as type II, took more time to avoid the saponin-added diet than others, even after the adverse effect of saponin became obvious. These results indicate that chicks may need some cues in order to differentiate between two diets more rapidly in the two-choice preference test.

Two groups of chicks were offered the choice between the basal diet and a diet containing $0.5 \%$ saponin in experiment 5 . The feeder positions of one group were changed every day and those of the other were fixed (Figure 2). When the feeder positions were changed every day as did in experiment 4 , feed intake of chicks fed the basal and saponin-added diets for $8 \mathrm{~d}$ was $58.6 \pm 4.6$ and $21.6 \pm 3.0 \mathrm{~g}$, respectively. Due to the lower saponin content in the diet, the proportion of the saponin-added diet consumed by chicks was apparently higher than that obtained in experiment 4 . On the other hand, fixing the feeder positions gradually decreased feed intake of the saponinadded diet as the experiment progressed. Consequently, feed intake of the basal diet $(80.8 \pm 3.5 \mathrm{~g} / 8 \mathrm{~d})$ and that of the saponin-added diet $(12.1 \pm 1.9 \mathrm{~g} / 8 \mathrm{~d})$ were significantly $(\mathbf{P}<0.01)$ different from the corresponding values of the unfixed group. Body weight gain during $8 \mathrm{~d}$ was also increased significantly $(\mathrm{P}<0.05)$ from $48.6 \pm 3.5$ $\mathrm{g}$ to $58.1 \pm 2.1 \mathrm{~g}$ by fixing the feeder positions. Thus, it seems likely that the feeder positions act as a cue for chicks to quit eating rapidly the saponin-added diet.

Results obtained from the present experiment indicate that chicks can recognize the presence of saponin in the diet by means other than taste. Force-feeding the diet containing alfalfa or tea saponin delays the crop emptying in chicks, which is overcome by adding cholesterol simultaneously to the saponin-added diet (Ueda et al., 1996 ; Ueda and Shigemizu, 1998). However, chicks did not show the special preference for cholesterol in the present experiment. In the preference test for $12 \mathrm{~h}$, the proportion of the saponin-added diet eaten by chicks decreased with time as shown in Table 2. 
Similarly, it was observed that the decrease in feed intake immediately after feeding the saponin-added diet $(0-2 \mathrm{~h})$ was rather mild and became severer with time $(2-4 \mathrm{~h})$ in the ad libitum feeding (Ueda, 2001). It was also reported that switching the saponinadded diet to the basal diet was more effective in increasing feed intake of the 2-4h period than that of the first $2 \mathrm{~h}$ (Ueda, 2001). The delayed crop emptying rather than taste or palatability may explain these observations. Chicks offered the two-choice preference test were able to discriminate between the basal and saponin-added diets quickly when the feeder positions were fixed. This result may be due to the learning by associating the feeling of disorder caused by delayed crop emptying with the feeder positions. This issue should be investigated in the next study.

\section{References}

Anderson, JO. Effect of alfalfa saponin on the performance of chicks and laying hens. Poultry Science, $36: 873-876.1957$.

Cheeke PR, Pedersen MW and England DC. Responses of rats and swine to alfalfa saponins. Canadian Journal of Animal Science, 58 : 783-789. 1978.

Cheeke PR, Powley JS, Nakaue HS and Arscott GH. Feed preference responses of several avian species fed alfalfa meal, high- and low-saponin alfalfa, and quinine sulfate. Canadian Journal of Animal Science, $63: 707-710.1983$.

Fenwick DE and Oakenfull D. Saponin content of food plants and some prepared foods. Journal of Science of Food and Agriculture, 34 : 186-191. 1983.

Heywang RW and Bird HR. The effect of alfalfa saponin on the growth, diet consumption, and efficiency of diet utilization of chicks. Poultry Science, $33: 239-241.1954$.

Heywang BW and Thompson CR. Effect of alfalfa saponin on laying chickens. Poultry Science, $38: 968-971.1959$.

Leamaster BR and Cheeke PR. Feed preferences of swine : Alfalfa meal, high and low saponin alfalfa, and quinine sulfate. Canadian Journal of Animal Science, 59 : 467-469. 1979.

Oakenfull D. Saponins in food-A review. Food Chemistry, $6: 19-40.1981$.

Ohshima $\mathrm{M}$ and Ueda $\mathrm{H}$. Effects of some treatments on the yield and the nutritive value of lucerne leaf protein concentrate. Japanese Journal of Zootechnical Science, $55: 584-590$. 1984.

Peterson DW. Some properties of a factor in alfalfa meal causing depression of growth in chicks. Journal of Biological Chemistry, $183: 647-653.1950$.

Price KR, Johnson IT and Fenwick GR. The chemistry and biological significance of saponins in foods and feedingstuffs. CRC Critical Reviews in Food Science and Nutrition, $26: 27-135$. 1987.

Ueda $\mathrm{H}$, Ohshima $\mathbf{M}$ and Kamada $\mathbf{M}$. The effects of processing methods and cholesterol addition on the nutritive value of leaf protein concentrates in chicks. Japanese Poultry Science, 23 : 195-202. 1986.

Ueda H. Effect of Gypsophila saponins on performance and plasma cholesterol concentrations in chicks fed the diets different in casein content. Animal Science and Technology, 63 : 905911. 1992.

Ueda H, Kakutou Y and Ohshima M. Growth-depressing effect of alfalfa saponin in chicks. Animal Science and Technology, 67 : 772-779. 1996.

Ueda $\mathbf{H}$. Effects of 18 amino acids individually added to the diets containing casein or soybean protein isolate on the serum cholesterol concentrations in chicks. Animal Science and Technology, 68 : 926-933. 1997.

Ueda $\mathbf{H}$ and Shigemizu G. Effects of tea saponin, cholesterol and oils on the growth and feed passage rates in chicks. Animal Science and Technology, $69: 14-21.1998$.

Ueda $\mathrm{H}$ and Tanoue K. Growth-depressing and cholesterol-lowering effects of Quillaja and tea saponins in chicks as influenced by diet composition. Animal Science Journal, $71:$ 390-396. 
2000.

Ueda H. Short-term feeding response in chicks to tea saponin. Journal of Poultry Science, 38 : 282-288.

Yoshida M. Design of Experiments for Animal Husbandry. pp. 125-162. Yoken-do. Tokyo. 1975. (in Japanese) 